\title{
Saudação do Prof. Vicente Ráo ao embaixador Raul Fernandes
}

"A Faculdade de Direito da Universidade de São Paulo orgulha-se de comemorar sua data magna, a da fundação de nossos cursos juridicos, recebendo em solene assenbléia universiária um seu filho ilustre, que estadistas de renome mundial, conferencias e congressos internacionais e centros universais de cultura dos mais famosos, de há muito consagraram como um dos maiores juristas contemporâneos; orgulha-se de receber de novo em seu seio o sr. dr. Raul Fernandes.

V. exa., sr. dr. Raul Fernandes, se em sua brilhante e gloriosa carreira sempre dedicou á defesa dos interesses supremos do Pais, na ordem interna e na ordem externa, o seu profundo saber juridico, nada mais fez do que prosseguir pelo caminho que se traçou ao iniciar os seus estudos superiores sob estas arcadas.

O calouro de 1895, colega de turma de Ernesto Pujol, Oscar Thompson, Alarico Silveira, José Augusto Cesar, Rafael Correia de Sampaio e outros, desde os primeiros instantes se destacou e se impôs, por seu talento e por sua conduta, á estima e ao respeito de seus mestres e de seus colegas, realizando o inteiro curso acadêmico com distinção e merecendo ser laureado com o premio de viagem á Europa.

Tamanho brilho, com que se sagrou cavaleiro do direito, havia forçosamente de lhe acompanhar e marcar todos os passos na caminhada que assim iniciava. 
E, na realidade, o traço predominante de toda a sua atuação, na vida publica, foi e continua a ser a sua intransigente fé no direito, em cujo estudo, já nos bancos academicos, alcançara as notas culminantes dos laureados.

No percurso dessa carreira notável, em escala constantemente ascendente, v. exa. palmilhou todos os degraus, dos mais simples aos mais elevados a que a ambição humana possa aspirar. Mas, esta ascensão não foi impulsionada por forças politicas apenas fiéis os seus interesses momentaneos, nem por momentaneas contigencias partidarias, nem por quaisquer conchavos que, um pouco por toda parte, nem sempre elevam ás culminancias os homens de maior merecimento.

A vida publica de v. exa. não é um rosario de sinecuras; representa, ao contrario, uma sucessão gloriosa de lutas para as quais v. exa. sempre foi con'vocado só e só por seu valor excepcional. E' uma vida belissima, digna de ser vivida, a de v. exa., a revelar um sentido profundamente humano, um contacto ininterrompido com todos os grupos sociais e politicos, a começar pelo municipio, a continuar pelo Éstado, a prosseguir pela Federação e a consagrar-se, afinal, nos grandes congressos e nas supremas assembléias internacionais.

Vereador e presidente da Camara Municipal de Vassouras, em seu estado natal, de 1898 a 1903; deputado estadual de 1903 a 1909; deputado federal de 1909 a 1918, e membro, na respectiva Camara, das Comissões de Finanças, de Justiça, de Diplomacia e Tratados, bem da Comissão Especial do Codigo Civil e do Codigo de Contabilidade Publica; delegado á Conferencia da Paz em 1918 e, a seguir, delegado junto ả Comissão de Reparações e membro do Comité de Juristas de Haia, para a elaboração do Projeto de Criação da Côrte Permanente de Justiça Internacional; delegado, de 1921 a 1925, á primeira, segunda, quarta e quinta Assemblẻias Gerais da Liga das Nações e convidado para o alto cargo de consultor juri- 
dico da Liga, cargo que não pode exercer porque então nos retirámos, em gesto de rara infelicidade, dessa organização internacional; embaixador na Belgica, em 1926 e 1927; chefe da delegação brasileira à Sexta Conferencia Pan-mericana de Havana, em 1928; membro do ConseIho Consultivo do Estado do Rio em 1931; Consultor Geral da Republica nesse mesmo ano; deputado á Constituinte de 1933 e relator geral da Constituição promulgada em 1934; de novo deputado federal e lider da maioria de 1934 até 1937, posto para o qual foi eleito, em 1934, após haver declinado do convite para o Ministério das Relações Exteriores; Presidente do Conselho da Ordem dos Advogados em 1943; delegado á Conferencia da Paz em 1946; chefe da delegação brasileira á Terceira Assembléia Geral da Organização das Nações Unidas; Ministro das Relações Exteriores de 1946 a 1950, periodo durante o qual, entre outras realizações notáveis, coube-lhe presidir a Conferencia de Petropolis, de que resultou o "Tratado do Rio de Janeiro", documento fundamental e criador da comunidade das nações americanas, segundo moldes internacionais substancialmente novos.

$\mathrm{E}$ mais ainda: arbitro em questões internacionais designado por paises estrangeiros, membro indicado pelos Estados Unidos da América do Norte para a comissão de arbitragem nas questões entre este Pais e a Checoslovaquia.

E não é só, nem eu pretendo enumerar todas as funções que exerceu, mas, apenas, encerrar esta indicação sumaria, lembrando que, no intervalo entre uma missão e outra, v. exa. sempre praticou a advocacia, consagrando-se em nossos pretorios como o jurista eminente, que todos nós veneramos.

Foram sinecuras essas missões todas e todos esses cargos por v. exa. exercidos? Não, não foram. Foram, antes, postos de combate, mas de combate em que só os gigantes vencem, como v. exa. venceu. 
Não é uma afirmação gratuita, esta que acabo de pronunciar; é, sim, a conclusão de um estudo cuidadoso da vida intelectual de v. exa., que devassei em todos os seus recantos, para extrair, dela, as diretrizes fundamentais de seu espirito.

Pelas idéias e não pela sucessão dos fatos é que a vida de um varão ilustre se define. E são estas idéias, estas diretrizes espirituais e intelectuais, que procurarei apresentar, nesta assembléia universitaria, como lição aos meus discipulos, como simbolo de uma existencia inteiramente dedicada, mais do que á Patria, á Humanidade.

Desde logo, causou-me impressão profunda a constante fidelidade de v. exa. ao conceito basico da

\section{UNIDADE E DA UNIVERSALIDADE DO DIREITO}

como meio único e supremo da existência de uma comunhão universal fundada na harmonia e não na discórdia, no amor e não no ódio, na paz e não na guerra.

Em conferência realizada em Montevideu, a 16 de maio de 1947, v. exa., reafirmando conceitos reiteramente expostos em oportunidades outras, fez suas estas palavras do eminente internacionalista POLITIS:

"Quando mais examinamos o inquietante problema da paz, mais nos persuadimos de que a condição primordial de sua solução é o progresso do direito. Já se disse com razão que nada pode substituir a guerra senão uma legislação internacional. Tal é a lição que se depreende nitidamente dos trabalhos realizados durante cinco anos pela Sociedade das Nações para cumprir a promessa de paz que o seu Pacto deu ao mundo. Procurou-se primeiramente a solução por meio de desarmamento e depressa se verificou ser impossível sem a segurança. Retornou-se a questão por êste lado e preciso foi reconhecer-se não haver segurança sem Justiça. Mas a Justiça precisa de leis, que o direito internacional ainda 
não nos deu. A conclusão inevitável, a que se chegou, é a de que a pedra angular da paz è o desenvolvimento do direito internacional".

E v. exa. amargamente acrescentou:

“A experiência está feita. Custou milhões de vidas humanas. Custou sofrimentos indiziveis que ainda se prolongam num crepusculo que devia anunciar a aurora da Idade Nova e, entretanto, se não acudirmos a tempo, pode preceder a noite da civilização... "A paz é a ordem baseadas na lei. Ela será precária enquanto teimarmos em baseá-la em tratados. Por mais justos que estes possam ser, cristalizam um statu quo. Esta concepção estatica da paz é inconciliável com o dinamismo da vida; tal a razão pela qual os contratos caducam, desajustados às novas circunstâncias e se rompem em guerras periodicas. A lei, ao contrário, assegura a paz duradoura, porque, tal como a própria vida de que é imagem, adapta-se às transformações continuas, seja por obra da jurisprudência, seja pela emenda do legislador atento às realidades."

Não bastava, entretanto, a simples afirmação da indeclinabilidade de uma lei internacional, a reger na convivência pacífica das nações. De mister se fazia fundamentar a asserção. E' v. exa. o fez brilhantemente, recordando que o direito, em seu fiel conceito substancial, ha-de revestir os requesitos de unidade e de universalidade. O problema disse v. exa., é de natureza identica nas relações humanas dentro ou além das fronteiras nacionais e só em gráu difere de uma zona para outra:

"Fronteiras a dentro, não passa pela cabeça de ninguém regular sòmente por meio de contratos e ajustes as relações de homem a homem, mesmo na esfera do direito pri-

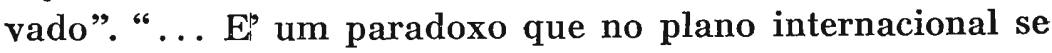
pretenda estabelecer sòmente por meio de ajustes as regras da convivência". — “... A segurança só se apoia na lei”. 
Esta desigualdade, esta cisão do conceito do direito, êste paradoxo, são a causa das maiores calamidades por que o mundo tem passado.

No entanto, a natureza bem diversa das coisas nos ensina, segundo sabias palavras que v. exa. já proferira a 23 de julho de 1925 perante a Sociedade Brasileira de Direito Internacional, que "o fato promordial e irredutivel é este, traduzido no adagio latino ubi societas ibi jus. Existe uma Sociedade de fato dos Estados, nascida de sua coexistência e das relações reciprocas dai derivadas. De modo mais ou menos consciente, o direito se elabora e se desenvolve nessa sociedade, formando um conjunto de regras de vida comum: - tal é o direito internacional. Ora, todo direito, para ser eficaz, supõe uma sanção que é, em última análise, um ato de fôrça ao serviço do direito violado. Êste elemento, indispensável à perfeição de uma disciplina jurídica, falta ao direito internacional: e, dada a sua ausência, os Estados fazem justiça por si mesmos, com os meios de fôrça de que dispõem: o ferro e o fogo, os explosivos e os gases, em última palavra, a guerra. $O$ resultado é que a independência, a fortuna e a própria existência dos Estados são coisas precárias, sujeita aos caprichos da fôrça. Tal situação não é apenas caotica e inorganica: - é contra a natureza e só se corrige pela instituição de uma autoridade dotada dos poderes e dos meios adequados a impor a observância da regra de direito."

E por que se manteve e mantém semelhante situação? Por que se não cria a lei internacional? Por que se não determina a sanção do direito externo? Por que se não institui uma autoridade dotada de poderes e meios para impôr a abservància da regra de direito?

A essas perguntas, que encerram em si todo o lancinante problema contemporaneo da sobrevivência, ou não, do direito internacional, respondeu v. exa. em mais de um passo de suas valiosissimas conferências e interven- 
ções em assembléias e cenaculos internacionais: - a causa desta situação está na convicção dos fortes de que, se um legislador internacional existisse, deveria ser obedecido e esta odebiência importaria restrição da soberania. Ao conceito e função da lei, os fortes continuam a sobrepôr o conceito e função de potência. Causa é esta, pois, que decorre do

\section{MITO DA SOBERANIA}

A liberdade, no entanto, só subsiste quando juridicamente disciplinada; e esta disciplina exige a imposição de restrições, para que todos possam ser livres. A liberdade absoluta é a negação da liberdade, porque equivale à vitoria do mais poderoso. Assim é na ordem interna, assim também é na ordem internacional. Se a convivên. cia humana, dentro de uma comunidade nacional, só é possível em regime de disciplina ou limitações, na convivência universal dos Estados outrotanto há-de suceder, sob pena de se proclamar que a razão do mais forte é sempre a melhor.

Na ordem interna, os homens sofrem, para bem de sua liberdade efetiva, as limitações impostas pelas leis e mesmo pelos contratos, cujo respeito coercitivamente pode ser reclamado; e o próprio Estado sofre as limitações ditadas pelo Estatuto Político ou Constituição aprovada pelo consenso do Povo. E se a soberania reside e emana do povo e não no Estado, porque, então, os Estados não hão de sofrer, na comunidade internacional, as restrições ditadas pela necessidade da preservação desta mesma comunidade?

V. exa. bem diagnoscou o mal e bem andou em estigmatizá-lo, quando ensinou e disse:

"o Pacto da Liga das Nações não rompeu com a tradição. Os homens políticos e os diplomatas que o elaboraram estavam, como os juristas, subjugados pelo mesmo mito pernicioso que o nacionalismo exalta para tormen- 
to da humanidade. Cedendo à contingência imperiosa deste fato social e mantendo intacta a arca santa da soberania, eles fizeram repousar o Pacto no príncipio do consentimento. O pacto efetivamente, não é mais do que uma convenção geral, cujo art. $10^{\circ}$ logo consagra o príncipio da retirada de qualquer dos aderentes mediante aviso com antecedência de dois anos. Ele não aspira, sequer, mesmo sob a forma convencional, a fundar uma disciplina que abarque a atividade internacional em todos os seus aspectos."

$\mathrm{E}$ por isso a primeira tentativa de se criar uma Or-ganização Internacional, falhou lastimàvelmente . Na estrutura e no funcionamento da Liga não penetrara o princípio democrático do prevalecimento do voto da maioria, embora qualificada. Ao contrário, por fidelidade à árca santa da soberânia, dispôs-se no Pacto que a criou, que "para salvaguarda da independência dos associados, a Assembléia delibera por unanimidade de votos das delegações presentes. Por exceção, a maioria é suficiente nas questões do processo e na confirmação das deliberações do Conselho, concernentes ao aumento do quadro de seus próprios membros. Uma maioria qualificada é exigida quando a Assembléia emenda o Pacto e quando delibera como mediadora."

Nem a experiência, a dolorosa experiência da guerra de 1914, nem a tragica prova da guerra de 1939 bastaram para demover os Estados mais poderosos desse mito fatal à humanidade.

E' certo que, ao se criar a Organização das Nações Unidas melhor disposição revelaram algumas das grandes potências para imprimir à nova entidade um sentido mais democrático. Mas, para evitar o fracasso da Orga-. nização que resultaria da retirada da Russia e de seus satelites, foi preciso ceder às contigências do momento, frutos de erros passados, aceitando-se a atribuição ao Con- 
selho de Segurança da competência privativa para a solução das questões fundamentais atinentes á manutenção da paz e preciso foi aceitar-se e admitir-se o direito de veto, de que os soviéticos têm usado e abusado, contra os interesses da paz, da paz que pregam e não praticam.

Mas, v. exa. jamais se calou ante essa deformação, ante esta perversão monstruosa dos interesses supremos da humanidade. E em conferências cientificas, em intervenções nas assembléias internacionais, sempre batalhou contra o mito da soberânia, fazendo desta batalha mais uma diretriz, constante e obedecida sempre, do espírito brilhante e profundamente humano de v. exa.

São reiterados, uniformes, às lições de v. exa. nesse sentido. V. exa, teve e tem, como ninguém, o sentimento da unidade e da universalidade do direito, a par do sentimento da unidade e da universalidade da paz, una e inscindível, pois guerra não há, em nossos dias, que a todo o universo não afete.

$\mathrm{E}$ v. exa. sentiu, ademais, que estas duas diretrizes permaneceriam letra morta se a elas não se ajuntassem princípios outros, complementares, tal, de inicio, o da

\section{IGUALDADE JURIDICA DOS ESTADOS}

principio em defesa do qual v. exa. tem sido um ardoroso e incansável continuador de RUI, de nosso RUI de Haia, RUI da conferência de Buenos Aires, RUI de nossas campanhas civicas maiores, RUI das mais gloriosas tradições jurídicas brasileiras.

Já a 21 de maio de 1921, perante a Academia Real de Jurisprudência e de Legislação de Madrid, v. exa. sustentava esta tese, em impressionante oração, que repercutiu profundamente nos meios internacionais, tese que eu me permito sintetizar neste simples axioma: assim como, na ordem interna, todos não iguais perante a lei e a lei é igual para todos, assim também, na ordem externa, todos os Estados devem ser iguais perante as leis 
internacionais e estas devem ser iguais para todos os Estados.

Da universalidade da lei internacional e da igualdade dos Estados perante esta lei, haveria de decorrer, necessàriamente, uma igual situação juridica para todos os Estados nas organizações das côrtes de justiça internacional.

Infelizmente, porém, "a desigualdade, sem disfarce, tem sido a regra. Quando Clemenceau surpreendeu' a Conferência da Paz (em 1918) com a famosa distinção entre potências principais e potências de interêsses limitados $\mathrm{e}$ quando o delgado belga Hymans protestou com a patetica interrogação "poderão dizer-me qual foi o interêsse particular que levou a Belgica à guerra?" - esta pergunta ficou sem resposta".

E nós por nossa vez, ainda hoje poderiamos perguntar: quererão dizer-nos qual foi o interêsse limitado que nos levou a enviar tropas brasileiras para além do Atlântico, a sacrificar a vida de patricios nossos, a perder uniJades valiosissimas de nossa marinha mercante e a sofrer as consequências do desiquilibrio econômico causado pela guerra? Também esta pergunta, se a formulassemos, ficaria sem resposta.

Sobravam razões a v. exa., portanto, quando nos cenáculos internacionais, se insurgia contra esta desigualdade, que tanto predominou na primeira, quanto na segunda conferência da paz, que tanto inspirou a formação da Liga das Nações, quanto a da Organização das Nações Unidas através de seus respectivos Conselhos e, até, em certo sentido, através das Côrtes de Justiça.

Perante o direito e perante a moral, a diferenciação quantitativa dos interêsses jamais poderia constituir um justo critério para a discriminação dos direitos. Nem, no estado atual das idéias políticas e jurídicas se poderia sustentar, a sério, o critério da subordinação das pequenas potências ás maiores, as quais, num simile de paterna- 
lismo medieval, tomariam a si o encargo de protegê-las. E menos ainda se justificaria o conselho regressivo de supostos internacionalistas que, como Walter Lippman, desprovidos do sentido da universalidade da paz, até hoje: sugerem a formação de zonas de influência e a exclusão, das organizações internacionais, dos itens atinentes á defesa coletiva.

Só e só aplausos, pois, conquistou e mereceu v. exa. quando se impôs como diretrizes, perante a Organização das Nações Unidas, a par do propósito de universalização dêste instituto, os seguintes conceitos: "tudo o que se relaciona com o bem-estar e a segurança de qual-quer um dos seus membros, deve ser objeto de igual consideração por parte dos demais"; "todos os membros da Organização devem possuir as mesmas prerrogativas, os mesmos direitos e equanime tratamento".

Assim v. exa. pensava ao se tentar organizar a paz em 1918; assim continuou a pensar de 1945 em diante, sem transigência, nem desfalecimentos.

Prova eloquente de quanto afirmo foi a atitude de $v$. exa., em 1947, recusando-se em nome do Brasil, a participar, por delegado especial, à Conferência de Londres, destinada á declaração da independência da Austria e a elaborar o estatuto da Alemanha, recusa que se justificou, de todo em todo, á vista das inaceitáveis limitações inıpostas á nossa atuação nesse conclave. $O$ protesto de v. exa., permito-me recordar, foi então secundado pelo Canadá, pelos Paises Baixos, pela África do Sul e pela Autralia.

Unidade e universalidade do direito, combate ao mito da soberania e igualdade jurídica dos Estados - eis três diretrizes fundamentais que nortearam a conduta de $v$. exa. no cenário internacional. Mas, não foram, nem poderiam ter sido, essas, as suas únicas idéias mestras. Perder-se-iam, por inocuas, se v. exa. não lhes acrescentasse, como acrescentou, o indispensável complemento da organização de uma 
JUSTIÇA INTERANACIONAL

digna deste nome. Ainda neste passo, reproduzirei palavras. de v. exa.:

,O ideal, de que precisamos nos aproximar cada vez mais, é o da Justiça obrigatória nos litigios puramente juridicos. Os juizes arłitros não suprem o indispensá'vel órgão judiciário internacíonal, cuja instituição os norte-americanos debalde se esforçaram por obter na Conferência de Haia de 1907. O proposito de constituir um tribunal pouco numeroso malogrou-se, então, como i sabido, pela intransigência dos grandes Estados em quererem ai se representar permanentemente por juizes de sua nomeação, enquanto os outros Estados se representariam rotativamente por juizes eleitos, consagrando-se, assim, uma desigualdade jurídica, que despertou oposição, não menos intransigente, chefiada com brilho e bravura inexcedíveis pelo nosso delegado Rui Barbosa. A Liga, cumprindo o art. 14 do Pacto, meteu ombros a esta empresa, preparando, logo no primeiro ano de sua existência, um Projeto, que a Assembléia aprovou unanimemente em 1920 e reuniu as ratificações necessárias a tempo de se elegerem os magistrados internacionais na Assembléia de 1921. Erigiu-se, assim, com sede em Haia, a Côrte Permanente de Justiça Internacional. O escolho em que naufragaram os diplomatas de 1907 foi engenhosamente contornado pelo Liga, prevalecendo o princípis da igualdade dos Estados. Este indiscutivel triunfo, imputável aos metodos e ao espírito que prevaleceram em Genebra, não foi completo, porque as grandes potencias se insurgiram contra o texto do Projeto, que fazia obrigatória a jurisdição do Tribunal, mediante citação de uma das partes pela outra. Mas, por uma emenda de undecima hora de iniciativa da delegação do Brasil, abriuse margem a que a obrigatoriedade da jurisdição existisse, sob reserva de reciprocidade, para os Estados que a ela quisessem se subordinar e assinassem para esse fim 
um protocolo, que permaneceu franqueado a ulteriores -adesões".

Essa emenda que v. exa. qualifica de undecima hora -e que, modestamente atribui à delegação do Brasil, representa uma de suas maiores vitoras no campo internacional, pois de sua iniciativa, exclusivamente sua, resultou a criação da Côrte, então ameaçada de novo malogro.

E por tal modo a feliz iniciativa de v. exa. correspondeu às necessidades e sentimentos gerais, que se perpetuou até aos nossos dias, transportando-se para o art. 36 n. 2 do Estatuto da atual Côrte Internacional de Justiça, criada, de acôrdo com o art. 92 da Carta de São Francisco, como principal órgão judiciário das Nações Unidas.

Deve-se a v. exa., praticamente, a criação desse órgão judiciário supremo; quem o afirma nada mais faz do que reproduzir fatos. E nem sou eu a afirmá-lo isoladamente, eu que, apenas, me reporto aos documentos da epoca. Helio Lobo, este notável internacionalista patricio, referindo-se a v. exa, e a este episódio, fundadamente escreveu:

"Criador, na verdade, ele o foi, pois quando se malograram todos os esforços para a instituição do arhitratamento obrigatório e a Comissão instituida pela Sociedade das Nações para a criação da Côrte se achava diante do velho impasse, foi dele que veio a formula salvadora".

Senhor doutor Raul Fernandes, eu poderia encerrar aqui, esta singela indicação de diretrizes jurídicas e espirituais pelas quais $v$. exa. batalhou com denodo inigualável durante decenios - singela indicação de idéias mestras reveladoras da real personalidade de um varão ilustre e com as quais ora comemoramos (e como poderiamos comemorar melhor?) a data que recorda a fundação dos cursos jurídicos brasileiros. 
Mas, algo mais tenho a dizer, por muito que já tenha dito. E, de logo, perguntarei: - foi proficua a pregação, por v. exa., dessas idéias básicas - a unidade e universalidade da conceituação do direito, o falso mito da soberania, a igualdade jurídica dos Estados e a Justiça Internacional efetiva?

Pecado que a humanidade paga desde a nascença $\dot{c}$ o de suportar um preço pesado e doloroso por suas conquistas no campo da civilização.

No setor interno como no externo, as idéias, por mais alevantadas que forem, jamais bastam para impelir os povos no caminho do melhoramento moral, social e político; ao contrario, elas só se afirmam, praticamente, após dolorosas experiências, quando não após lutas sangrantas e fraticidas, isto é, à custa de lágrimas, suor e sangue.

Mas são elas, as idéias, as sementes fecundas que acabam por germinar um dia.

A pregação de v. exa. não foi perdida, pois, apesar do tumulto político contemporâneo, apesar da divisão do mundo em duas partes incomunicáveis, realizámos progressos sensíveis no sentido da realização dos ideais que v. exa. semeou.

Em primeiro lugar, asinalarei o trabalho realizado pela Organização das Nações Unidas por seus instintos idestinados ora á codificação do direito internacional, ora à tentativa da uniformização do direito privado, ora ao desenvolvimento das ciencias e da artes, ora á realização de obras e serviços assistenciais.

Assinalarei, a seguir, ainda no setor da Organização das Nações Unidas, a reação da maioria de seus membros contra a uso do veto, no Conselho de segurança, em materia referente á segurança da paz. Sob a orientação de v. exa., coube-me a honra de sustentar, perante a Comissão Politica da ONU, em 1950, o ponto de vista do govêrno brasileiro contrario ao veto, nestes casos, demons- 
trando o absurdo de se conferìr a um órgão da entidade poderes maiores dos atribuidos à própria organização, representada por sua assembléia geral e, assim, poderosamente contribuimos para a aprovação da proposta norteamericana, para a segurança da paz.

E', sem dúvida, um avanço, êste que acabo de mencionar e ao qual se devem acrescer os esforços da Organização no sentido de debater e aprovar um projeto elaborado por sua Secretaria definindo, sôbre a base da igualdade, os direitos e deveres dos Estados.

Direi, mais, que a Declaração Universal dos Direitos do Homem, promulgada pela ONU, é um documento substancial de nosso tempo, que, em contraste com a Declaração dos Direitos do Homem e do Cidadão proclamada pela Revolução Francesa, marca a passagem da fase individualista para a fase social do direito interno e externo, contribuindo para a vitoria, a ser alcançada um dia, da conceituação unitaria do direito.

$\mathrm{E}$, por fim, assinalarei um progresso maior, que representa verdadeira transformação no campo do direito internacional.

Quero referir-me ao Tratado do Rio de Janeiro aprovado pela Conferencia de Petropolis e complementado pela Conferencia de Bogotá.

Da Conferencia do Rio de Janeiro, v. exa., então ministro das Relações Exteriores, não foi, apenas, o seu presidente, mas também o seu inspirador e orientador e o Tratado, que dela resultou e tanto the deve, corresponde, v. exa. bem o disse, à introdução do processo e do principio democratico nas organizações e assembléias internacionais e, pois, na disciplina das relações entre Estados.

A Liga das Nações falira, por se basear no principio do consentimento unanime; a Organização das Nações Unidas ainda se debate entre as dificuldades criadas pelo veto, apesar da redução da eficiencia deste recurso dissolvente imposto pelos sovieticos. 
Relembrando as causas desses insucessos, bateu-se v. exa. em Petropolis pelo princípio da maioria qualificada e obtendo o apoio da grande nação norte-americana, conquistou uma esplendida vitoria, uma vitoria total.

Foi mais longe este salutar tratado ao definir e caracterizar os casos de agressão, ao estabelecer a defesa mutua e obrigatoria, ao dar vida aos orgãos superiores da nova organização dos Estados Americanos.

$E$ v. exa. que outrora tivera tantas palavras amargas e de desengano, agora, ante o predominio do principio da igualdade dos Estados, ante o predominio do princípio democratico na organização das nações americanas, ante o fato da criação de verdadeiras normas juridicas internacionais e de sua sanção, agora v. exa, entôa o cantico da esperança e da vitoria e proclama na sessão de encerramento da Conferencia:

"Somos agora uma familia de nações que aos vinculos morais inerentes a toda a sociedade familiar, acrescentou um nexo juridico, por força do qual assumimos uns para com os outros duas obrigações de capital importancia; proscrevemos a guerra como instrumento da politica e organizamos a solidariedade de nossas Republicas para repelir o ataque armado contra qualquer delas, venha de onde vier e onde quer que aconteça... Julgo necessario dar um merecido relevo às estipulações do Tratado, segundo as quais as decisões do orgão de consulta, tomadas pela maioria de dois terços dos Estados signatarios que o tenham ratificado, serão obrigatorias para todos, mesmo quando apliquem sanções diplomaticas, economicas, comerciais ou financeiras, com a unica exceção de que nenhum Estado será obrigado a empregar a força armada sem o seu consentimento. Com ele abre-se uma brecha no reduto das soberanias nacionais ilimitadas, e, posto que sua aplicação se limite a um caso determinado, é manifesto que aí se estabelece uma regra democratica cujos corolarios estão à vista e nos deixam entrever, entre 
outras possibilidades, a de uma legislatura que, definindo o licito e o ilicito nas relações entre os Estados, substitua na vida internacional o principio de potencia pelo da ordem baseada na lei, propiciando liberdade e justiça. Os Estados Americanos torcem, neste passo, os caminhos dos continentes - e, esperemos, mais tarde os do mundo - para destinos mais altos, mais humanos e mais generosos; fixam a data historica em que se lançam os fundamentos de um genuino direito internacional; e, se todos trazem a sua contribuição ao abdicar de algumas faculdades até agora tidas por soberanas, è justo consignar que a mais importante oferenda é a dos Estados Unidos da America, hoje a nação mais poderosa que existiu em todos os tempos".

Como não havia v. exa. de se sentir feliz pela realização de um de seus sonhos mais carinhosos, pelo qual sempre se bateu em beneficio da humanidade? E quão feliz não se ha de sentir v. exa. ao verificar o exito de seu vaticinio no sentido da extensão dos principios consagrados pelo Tratado do Rio de Janeiro?

Porque, de fato, essa extensão se operou e vem se operando ainda. 0 mais ligeiro confronto do Pacto do Rio de Janeiro com o Pacto do Atlantico Norte, que se lhe seguiu, demonstrará o quanto este foi inspirado por aquele e tudo leva a crer que, mutatis mutandis, os mesmos principios informarão o Pacto do Pacifico em vias de elaboração.

Não foi improficua, pois, a pregação, por v. exa., das. diretrizes que destaquei de sua atuação na vida publica, pois a v. exa. coube a fortuna de contribuir, quando menos, para um começo efetivo da realização e da pratica destes ideais.

Por nada não foi, sr. dr. Raul Fernandes, que, certa vez, quando lhe coube preservar, em uma conferencia internacional, a União Pan-Americana, um autorizado periodico da grande Republica do Norte proclamou seu 
valor pouco comum e afirmou que os Estados Unidos viveriam tranquilos, na comunhão dos povos, enquanto. pudessem contar com amigos de tão alto quilate.

Não foi por nada, sr. dr. Raul Fernandes, que o presidente Truman, após haver assistido à assinatura do Tratado do Rio de Janeiro, felicitou o presidente Dutra, o general que foi o mais civil de nossos presidentes, por ter o ministro do exterior que tinha.

Nem por nada o secretario de Estado norte-americano Marshall declarou à imprensa carioca que v. exa. era a figura que mais o impressionara naquela Conferencia historica, na qual foi semeada a futura organização universal da paz, que surgirá quando as cortinas de ferro cairem ao sopro da liberdade e de novo todos os povos do universo, todos eles livres, se juntarem em uma estreita comunhão de vida. $E$ então v. exa. verá o seu sonho de paz totalmente realizado segundo estes ensinamentos cristãos que fez seus:

"S. Paulo disse em palavras de ouro na Epistola aos Colossenses: "não ha grego, nem judeu circunciso ou incircunciso, barbaro, sita, servo, ou livre: Cristo é tudo em todos". E na Epistola aos Corintios: "quando eu falar todas as linguas dos homens e mesmo a dos anjos, se não tiver caridade serei como o bronze ou como o cimbalo estridente. E quando tiver o dom da profecia, e conhecer todos os misterios e possuir toda a ciencia, quando tiver o maximo de fé e puder transportar as montanhas, se não tiver caridade não serei nada". Ai estão os dois pilares indestrutiveis da paz: - a fraternidade e a caridade. Entre os homens, entre as nações, desde sempre e para sempre".

Ao terminar seu curso academico recebeu v. exa. nesta Casa a laurea de primeira aluno de sua turma. Longos anos passados, anos de lutas e de vitorias, de sacrificios e de glorias, que de v. exa. fizeram um dos mais ilustres. varões do Brasil e da humanidade, v. exa. volta ás Arcadas, 
ás velhas Arcadas franciscanas desta nossa escola gloriosa, para receber o premio maior que ela possa conferir e v. exa. merece par droit de conquête.

Do orgulho que sentimos pelos sucessos de v. exa., por seu valor excelso, diz a circunstancia de havermos escolhido a data historica que hoje comemoramos, para sagrá-lo doutor honoris causa.

$E^{\prime}$ que a vida de v. exa. é uma lição sublime para a nossa juventude academica, pois de homens assim é que precisamos para realizar nossos destinos de progresso e de paz no mundo.

Não nos iludamos. O ciclo da civilização corre no tempo e no espaço. E' historico e geografico e a Historia nol-o ensina. O Oriente, a Africa, o Ocidente, a America do Norte, marcam apogeus desse ciclo grandioso que, um dia, fatalmente alcançará a America do Sul e, na America do Sul, o Brasil.

Somos, todos, os artifices da epopéia sublime da formação da grande patria presente e da patria maior e primeira do mundo futuro, para transmitirmos, um dia, 20 universo os nossos ideais cristãos de paz e de fraternidade.

E o nome de v. exa. continuará a ser laureado pelas gerações vindouras, pelos espiritos conscientes dos valores reais de nossa nacionalidade.

Quando v. exa., em plataforma dirigida ao eleitorado de seu Estado, se candidatou à Presidencia, propôs-se manter alheio à politica dos partidos e disse:

"estas condições, penso eu, são dignas de vós e de mim. Não serei o governo "forte" de que vos falei a principio; renuncio convencidamente aos melhores instrumentos de captação e ficarei provavelmente sem sequito nem cortejo; mas aspiro a ser forte por outro modo, isto é, na estima publica e no juizo de minha propria consciencia".

Não falhou o vaticinio de v. exa. porque, se tão nobre proclamação de honestidade politica desagradou 
aos poderosos de então e lhe causou o esbulho violento do mandato que o eleitorado ihe conferira, v. exa. ficou, de fato, sem o sequito e sem o cortejo dos bajuladores que costumam envolver os poderosos de cada dia, mas se fortaleceu na estima publica, na consciencia dos homens de bem, na consagração de seu nome pelos estadistas e internacionalistas de fama mundial, no respeito das maiores assembléias universais, que, uma delas, certa feita, fez de v. exa., de simples suplente ou assessor, que era, de um ilustre delegado ausente, fez de v. exa., repito, um delegado plenipotenciario, conferindo-lhe, contra o estatuto regimental, por iniciativa, não do nosso, mas dos governos estrangeiros, os direitos de intervenção direta e de voto, que em rigor não lhe com. petiam, mas que seu valor incomum conquistara.

$\mathrm{E}$ nesta solenidade, que é a nossa solenidade maxima, arranca v. exa., merecidamente, o maior galardão universitario, o titulo de doutor honoris causa, que lhe confere a Faculdade de Direito de São Paulo, esta velha Faculdade que abrigou e preparou para a vida publica as maiores figuras de nossa historia, esta escola centenaria que outrora acolheu o calouro Raul Fernandes, um moço cheio de sonhos e de esperanças, e agora de novo recebe a aplaude este seu filho dileto e se envaidece e se orgulha e está em festas por poder premiar e consagrár o Raul Fernandes realizador de seu's sonhos e de suas esperanças de moço, o jurista, o estadista, o patriota, o antigo aluno que, honrando as tradições destas Arcadas, aqui volta coberto de glorias, que são também nossas, porque nesta escola v. exa. iniciou a sua formação juridica e por que foram as suas glorias conquistadas a serviço e a bem de nossa Terra". 